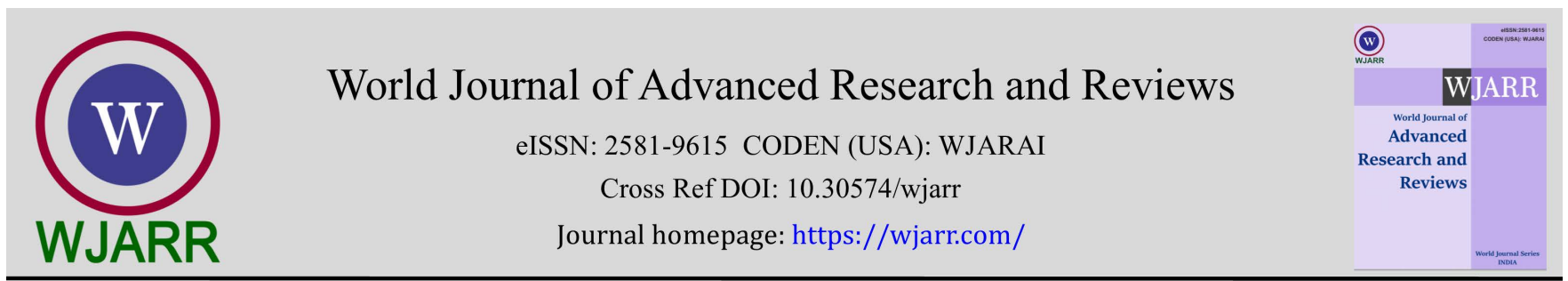

(RESEARCH ARTiClE)

Check for updates

\title{
In vitro antioxidant and anti-inflammatory activities of methanol extract of Vitellaria paradoxa seed (shea seed)
}

\author{
Babafemi Tosin Ogunbiyi 1, *, Oluwaseyi Adegoke Adetunji 1, Olubunmi Esther Ogunbiyi 2, Gogonte Hezekiah \\ Amah ${ }^{1}$, Modupe Olusola Adetayo ${ }^{1}$ and Laide Omoyiola Olajide ${ }^{1}$ \\ ${ }^{1}$ Department of Biochemistry, School of Basic Medical Sciences, Babcock University, Ilishan-Remo, Ogun State, Nigeria.
${ }^{2}$ Department of Anatomy, School of Basic Medical Sciences, Babcock University, Ilishan-Remo, Ogun State, Nigeria.
}

World Journal of Advanced Research and Reviews, 2021, 11(03), 057-065

Publication history: Received on 31 July 2021; revised on 02 September 2021; accepted on 04 September 2021

Article DOI: https://doi.org/10.30574/wjarr.2021.11.3.0422

\begin{abstract}
Vitellaria paraodoxa (shea tree) is the source of shea seed from which the well-known shea butter is derived. The methanol extract of shea seed was evaluated for its anti-inflammatory and antioxidant activities using diclofenac sodium and ascorbic acid as standard respectively in in vitro methods. The anti-inflammatory activity was determined by inhibition of protein denaturation of bovine serum albumin (BSA) and erythrocyte membrane stabilization of human red blood cell. The antioxidant activity was evaluated using 1, 1-diphenyl-2-picrylhydrazyl (DPPH), ferric reducing antioxidant power (FRAP), thiobarbituric acid reactive substances (TBARS) and total antioxidant capacity (TAC) assays. The results showed that methanol extract of $V$. paradoxa seed at different concentration protects the heat induced protein denaturation with the maximum percentage inhibition of $27 \%\left(\mathrm{IC}_{50}=303.0 \mu \mathrm{g} / \mathrm{mL}, \mathrm{p}<0.05\right)$ at $500 \mu \mathrm{g} / \mathrm{mL}$ compared to the standard drug which induced maximum inhibition of $45 \%$ ( IC $50=261.4 \mu \mathrm{g} / \mathrm{mL}, \mathrm{p}<0.05$ ) at $500 \mu \mathrm{g} / \mathrm{mL}$ and the control. The percentage inhibition of the methanol extract and standard drug in erythrocyte stabilization assay increased in a concentration dependent manner with maximum inhibitory activity of $96.9 \%\left(\mathrm{IC}_{50}=31.47 \mu \mathrm{g} / \mathrm{mL}, \mathrm{p}<0.05\right.$ ) and $95 \%\left(\mathrm{IC}_{50}=33.89 \mu \mathrm{g} / \mathrm{mL}, \mathrm{p}<0.05\right.$ ) at $2000 \mu \mathrm{g} / \mathrm{ml}$ respectively, which indicates that methanol extract stabilized erythrocyte membrane against hypotonic induced hemolysis in a blood sample better than the standard drug. The maximum percentage inhibition of methanol extract and standard drug in DPPH assay were found to be at $97 \%$ $\left(\mathrm{IC}_{50}=8.95 \mu \mathrm{g} / \mathrm{mL}, \mathrm{p}<0.05\right)$ and $98 \%\left(\mathrm{IC}_{50}=6.72 \mu \mathrm{g} / \mathrm{mL}, \mathrm{p}<0.05\right)$ respectively at $100 \mu \mathrm{g} / \mathrm{ml}$. The absorbance of the reductive capacities in FRAP assay indicates that the methanol extract has higher reducing potency in a concentration dependent manner. The methanol extract exhibited total antioxidant capacity of $0.25 \pm 0.04 \mu \mathrm{g} /(\mathrm{AAE} / \mathrm{g}) \mathrm{when}$ compared to the standard drug $0.87 \pm 0.03 \mu \mathrm{g} /(\mathrm{AAE} / \mathrm{g})$ at highest concentration of $100 \mu \mathrm{g} / \mathrm{ml}$. For TBARS assay, low absorbance value indicate a high level of inhibition of lipid peroxidation. The maximum percentage inhibition of methanol extract was $97.5 \%\left(\mathrm{IC}_{50}=51.79 \mu \mathrm{g} / \mathrm{mL}, \mathrm{p}<0.05\right)$ and ascorbic acid was $99 \%\left(\mathrm{IC}_{50}=52.30 \mu \mathrm{g} / \mathrm{mL}, \mathrm{p}<0.05\right)$ at concentration of $20 \mu \mathrm{g} / \mathrm{ml}$. The assay indicates that the methanol extract has higher inhibiting potency in a reverse concentration dependent manner. In conclusion, $V$. paradoxa seed may possess strong anti-inflammatory and antioxidant activities which could constitute a potential source for development of new therapy.
\end{abstract}

Keywords: Vitellaria paradoxa; Anti-inflammatory; Antioxidant; Inhibition

\section{Introduction}

Medicinal plants are of great importance to the health of humans. Medicinal plants are plants that are used to attempt to maintain health, to be administered for a specific condition or both, whether in modern or traditional medicine [1]. The parts of the plants used for medicine may be their leaves, flowers, roots, seeds or bark. Treatment with medicinal

\footnotetext{
* Corresponding author: Babafemi Tosin Ogunbiyi

Department of Biochemistry, School of Basic Medical Sciences, Babcock University, Ilishan-Remo, Ogun State, Nigeria. 
plants is considered very safe as there is no or minimal side effects. The medicinal value of these plants lies in some of their bioactive constituents (like alkaloids, tannins, flavonoids and phenolic compounds) that produce a definite physiological action on the human body [2, 3]. According to World Health Organization (WHO), around 21, 000 plant species have the potential for being used as medicinal plants. WHO estimated that $80 \%$ of people worldwide rely on herbal medicines for some aspect of their primary health care needs [4].

Vitellaria paraodoxa (shea tree) belongs to the Sapotaceae family. It is the source of shea seed from which the wellknown shea butter is derived. Shea tree can be found growing in savannah belt region in countries including Senegal, Mali, Côte d'Ivoire, Burkina Faso, Togo, Ghana, Benin, Nigeria, Niger, Cameroon, Uganda, Sudan and Ethiopia [5]. The shea seed is a hard brown shell that contains the fatty kernel. The shea seed is not edible, it is primarily used to extract shea butter and shea nut oil, rich in nourishing fatty acids and healing components [6]. The chemical composition of the kernel of the seed per $100 \mathrm{~g}$ dry matter are approximately, 31-62 g fat, 7-9 g protein, 31-38 g carbohydrate, 2.5-12 g unsaponifiable matter. The non-fat part (kernel) is composed of phenols: tocopherols, triterpenes (alpha-amyrin, lupeol, butyrospermol, parkeol), steroids (campesterols, stimasterol, beta-sitosterol, alpha-spinasterol, delta-7-avanasterol), and hydrocarbons (2-3\% karitene). It also contains terpenic alcohols [7].

Inflammation is the organism's protective response to several stimuli, prolonged inflammatory response or occurrence where it is not needed is fatal to the body system. It involves occurrence such as; increase of vascular permeability, increase in protein denaturation and membrane alteration. Researchers recognize inflammation as a key components of many of the major diseases affecting human health. It sometimes contributes to the damage of the very tissue it is evolved to protect. The human body naturally produces free radicals and the antioxidants to counteract their damaging effects. The generation of free radicals in excess amount outnumber that naturally occurring antioxidants and induce oxidative stress which is associated with many degenerative human diseases such as accelerative aging, certain cancers, diabetes, cardiovascular diseases, inflammation and neurodegenerative diseases have been recognized to be associated to free radicals damage [8]. In order to maintain the balance, a continual supply of external sources of antioxidants is necessary to obtain the maximum benefits of antioxidants. Antioxidant agents benefit the body by neutralizing and removing the free radicals. The synthetic anti-oxidative and anti-inflammatory drugs have a number of adverse side effects, such as gastrointestinal discomfort, inhibition of platelet aggregation, and liver and kidney toxicity [9]. Thus, there is considerable research interest in the identification of new anti-inflammatory and anti-oxidative agents from plants used in traditional medicine. Therefore, this study was designed to investigate the anti-inflammatory and antioxidant activities of methanol extract of shea seed (V. paradoxa).

\section{Material and methods}

\subsection{Sample collection and processing}

Shea seeds were obtained from Oje market at Ibadan, Oyo state. It was dehulled, washed and dried in a hot air oven at $40^{\circ} \mathrm{C}$ for 14 days. The seed were pulverized using blending machine. The extract was obtained by weighing $100 \mathrm{~g}$ of ground shea seed and $800 \mathrm{ml}$ of $70 \%$ for maceration with intermittent shaking for 72 hours. The extract was filtered using Whatman filter paper and the filtrate was subsequently concentrated using the rotary evaporator at $40^{\circ} \mathrm{C}$. The concentrate was oven dried and kept at $4^{\circ} \mathrm{C}$ for further use.

\subsection{In vitro Anti-inflammatory Assays}

\subsubsection{Inhibition of protein denaturation assay}

Anti-denaturation of BSA was assayed using a modified method of Ramalingam et al. (2010) [10]. The assay mixture contained test solution of BSA $(45 \mu \mathrm{L}, 0.5 \% \mathrm{w} / \mathrm{v})$ and $5 \mu \mathrm{L}$ of methanol extract of $\mathrm{V}$. paradoxa prepared in various concentrations $20,40,60,80$ and $100 \mu \mathrm{L} / \mathrm{mL}$ respectively. The mixture was incubated at $37^{\circ} \mathrm{C}$ for 20 mins in a water bath (Uniscope SM801A; Surgifield Medicals) and the temperature was increased to keep the samples at $57^{\circ} \mathrm{C}$ for 3 mins. After cooling, $2.5 \mathrm{ml}$ of phosphate buffer saline ( $\mathrm{pH} \mathrm{6.3)} \mathrm{was} \mathrm{added} \mathrm{to} \mathrm{each} \mathrm{mixture} \mathrm{in} \mathrm{the} \mathrm{tube.} \mathrm{The} \mathrm{absorbance} \mathrm{was}$ measured at $416 \mathrm{~nm}$ using a spectrophotometer. $45 \mu \mathrm{L}$ distilled water and $5 \mu \mathrm{L}$ of test solution (BSA and V. paradoxa extract) were used as test control. The experiment was carried out in triplicates and percentage inhibition for protein denaturation was calculated. The $\mathrm{IC}_{50}$ was estimated using linear regression equation.

\subsubsection{Human red blood cell (HRBC) membrane stabilization assay}

The effect of methanol extract of V. paradoxa seed on hypotonicity-induced hemolysis of human red blood cell membrane (HRBC) was carried out in accordance to the protocol described by Oyedapo (2010) [11]. Fresh human whole blood ( $5 \mathrm{ml}$ ) was obtained using a $5 \mathrm{ml}$ syringe and transferred into an ethylenediamine tetraacetic acid (EDTA) bottle. 
The EDTA bottle containing the whole blood was centrifuged at 3000rpm for 10 mins, and the supernantant (plasma and leucocytes) were carefully discarded while the packed red blood cells were washed in fresh normal saline $(0.9 \%$ $\mathrm{w} / \mathrm{v} \mathrm{NaCl}$ ). The process of washing and centrifuging was repeated until the supernatant was clear. 10\% HRBC membrane was then resuspended in $0.9 \% \mathrm{w} / \mathrm{v} \mathrm{NaCl}$ as stock. The assay mixture contained 1 ml of sodium phosphate buffer $(0.15 \mathrm{M}, 7.4 \mathrm{pH}), 2 \mathrm{ml}$ hyposaline $(0.36 \% \mathrm{w} / \mathrm{v} \mathrm{NaCl}), 0.5 \mathrm{ml}$ HRBC suspension $(10 \% \mathrm{w} / \mathrm{v})$ with $0.5 \mathrm{ml} \mathrm{diclofenac}$ sodium as standard drug or methanol extract preparations of varying concentrations in test tubes. For the control, distilled water replaced $\mathrm{NaCl}(0.36 \%, \mathrm{w} / \mathrm{v})$ to induce $100 \%$ hemolysis. The hemolysis produced in the presence of distilled water was taken as $100 \%$. The different test tubes were incubated at $56^{\circ} \mathrm{C}$ in a water bath (Uniscope SM801A; Surgifield Medicals) for $30 \mathrm{~min}$ and then centrifuged at $5000 \mathrm{rpm}$. The hemoglobin content in each tube was estimated spectrophotometrically at $560 \mathrm{~nm}$. The experiment was performed in triplicates for all the test samples. The percentage of HRBC membrane stabilization was calculated using the formula;

$$
\text { Percentage Stabilization }=100-\frac{\text { Optical density of extract }}{\text { Optical density of control }} \times 100
$$

\subsection{In vitro Antioxidant Assays}

\subsubsection{1, 1-diphenyl-2-picryl hydrazyl (DPPH) radical scavenging assay}

DPPH radical scavenging activity was determined as described by Molyneux (2004) [12], with slight modifications. 1 ml of $0.2 \mathrm{mM}$ DPPH prepared with methanol was added to $2.5 \mathrm{ml}$ solution of varying concentrations of methanol extract of V. paradoxa seed and ascorbic acid as standard at different concentrations of 20, 40, 60, 80 and $100 \mu \mathrm{g} / \mathrm{mL}$ and allowed to react at room temperature in darkness for $30 \mathrm{~min} .1 \mathrm{ml}$ of $0.2 \mathrm{mM} \mathrm{DPPH}$ and $2.5 \mathrm{ml}$ methanol served as a control. This assay was carried out in triplicates for each concentration. Absorbance of the resultant mixture was measured using the double beam UV-visible spectrophotometer (Model T80; PG Instruments, Lutterworth, England, UK) at 517 $\mathrm{nm}$. Percentage inhibitions of the methanol extract and the standard were calculated using the formula below:

$$
\% \text { inhibition }=\frac{\text { Optical Density control }- \text { Optical Density sample }}{\text { Optical Density control }} \times 100
$$

Percentage inhibition indicates the capacity of fractions to inhibit reactive oxygen species, and the concentration of sample required for $50 \%$ inhibition was determined and expressed as an $\mathrm{IC}_{50}$ value.

\subsubsection{Ferric reducing antioxidant potential assay}

Ferric reducing assay was done using the method described by Benzie and Strain (1999) [13]. A solution of $2.5 \mathrm{~mL} 0.2$ $\mathrm{M}$ phosphate buffer (pH 6.6) and $2.5 \mathrm{ml}$ potassium ferricyanide $(1 \% \mathrm{w} / \mathrm{v}$ ) was added into test tubes containing $1 \mathrm{~mL}$ methanol extract of $\mathrm{V}$. paradoxa at different concentrations. The reaction mixtures were incubated at $50^{\circ} \mathrm{C}$ for $30 \mathrm{~min}$, followed by the addition of trichloroacetic acid $(2.5 \mathrm{~mL} 10 \% \mathrm{w} / \mathrm{v})$. The reaction mixtures were centrifuged at $3000 \mathrm{rpm}$ for $10 \mathrm{~min}$, and the upper layer of the solution was collected. A volume of $2.5 \mathrm{ml}$ supernatant solution was mixed with $2.5 \mathrm{~mL}$ distilled water and $0.5 \mathrm{~mL} \mathrm{FeCl} 3(0.1 \% \mathrm{w} / \mathrm{v})$. The absorbance was then measured at $700 \mathrm{~nm}$ against blank sample using the double beam UV-visible spectrophotometer (Model T80; PG Instruments, Lutterworth, England, UK). Ascorbic acid was used as the standard.

\subsubsection{Thiobarbituric acid reactive species assay}

Thiobarbituric acid reactive substances (TBARS) assay was carried out using the method described by Hodges et al. (1999) [14]. Varying concentrations of ascorbic acid were prepared and made up to $1.0 \mathrm{ml}$ in test tubes using distilled water. Similarly, varying concentrations of methanol extract of V. paradoxa seed was prepared and made up to $1.0 \mathrm{ml}$ using distilled water. $2 \mathrm{ml}$ of $20 \%(\mathrm{w} / \mathrm{v}$ ) trichloroacetic acid and $2 \mathrm{ml}$ of $0.67 \%(\mathrm{w} / \mathrm{v}$ ) of thiobarbituric acid solutions were added to these test solutions. Blank was also prepared in another set of tubes containing the above reagents without any sample. The test tubes were placed in a boiling water bath for $10 \mathrm{~min}$, cooled and centrifuged at $3000 \mathrm{rpm}$ for $20 \mathrm{~min}$. Absorbance of supernatants was measured at $552 \mathrm{~nm}$ using the double beam UV-visible spectrophotometer (Model T80; PG Instruments, Lutterworth, England, UK). This assay was carried out in triplicate and percentage inhibition of lipid peroxidation (\%) was calculated according to the formula below:

$$
\% \text { inhibition }=\frac{\text { Optical Density control }- \text { Optical Density sample }}{\text { Optical Density control }} \times 100
$$

Optical Density control $=$ The absorbance without sample, 
Optical Density sample $=$ The absorbance of methanol extract or standard.

\subsubsection{Total antioxidant capacity (TAC)}

TAC assay was determined using modified phosphomolybdate method as described by Prieto et al. [15]. $0.1 \mathrm{ml}$ of methanol extract of $\mathrm{V}$. paradoxa seed in different concentration ranging from 20 to $100 \mu \mathrm{l}$ were added to each test tube, $1 \mathrm{ml}$ of Molybdate reagent ( $0.6 \mathrm{M}$ sulfuric acid, $28 \mathrm{mM}$ sodium dihydrogen phosphate, and $4 \mathrm{mM}$ ammonium molybdate) was also added. The standard consisted of $0.1 \mathrm{ml}$ of varying concentrations of $1 \mathrm{mg} / \mathrm{ml}$ ascorbic acid in distilled water with $1 \mathrm{ml}$ working reagent. Solutions were incubated in a water bath (Uniscope SM801A; Surgifield Medicals, Okehampton, England, UK) for $90 \mathrm{mins}$ at $95^{\circ} \mathrm{C}$ and then allowed to cool. At room temperature, the absorbance of the sample mixture was measured at $695 \mathrm{~nm}$ against a blank ( $1 \mathrm{ml}$ of Molybdate reagent and $0.1 \mathrm{ml}$ of distilled water) using a double beam ultraviolet (UV)-visible spectrophotometer (Model T80; PG Instruments, Lutterworth, England, UK) against a blank solution containing $0.1 \mathrm{ml}$ distilled water and $1 \mathrm{ml}$ working reagent incubated under the same condition. Mean values from three independent samples were calculated for the extract. TAC was expressed as equivalents of ascorbic acid per ml sample.

\subsection{Statistical analysis}

Statistical analysis and graphical presentations were performed using GraphPad Prism ${ }^{\circledR} 6.0$ software. It was used for computing the $\mathrm{IC}_{50}$ values for antioxidant and anti-inflammatory assays. Values were reported as a mean \pm standard error of the mean of triplicate readings.

\section{Results and discussion}

Data from figure 1 showed that Diclofenac sodium and methanol extract of $V$. paradoxa seed (VPSME) inhibited heatinduced protein denaturation in a concentration-dependent manner. Maximum inhibition was shown at $500 \mu \mathrm{g} / \mathrm{mL}$ for both Diclofenac sodium and the methanol extract. Furthermore, Diclofenac sodium $\left(\mathrm{IC}_{50}=261.4 \mu \mathrm{g} / \mathrm{mL}, \mathrm{P}<0.05\right) \mathrm{had}$ higher anti-denaturation potential than methanol extract of $V$. paradoxa seed $\left(\mathrm{IC}_{50}=303.0 \mu \mathrm{g} / \mathrm{mL}\right.$ ).

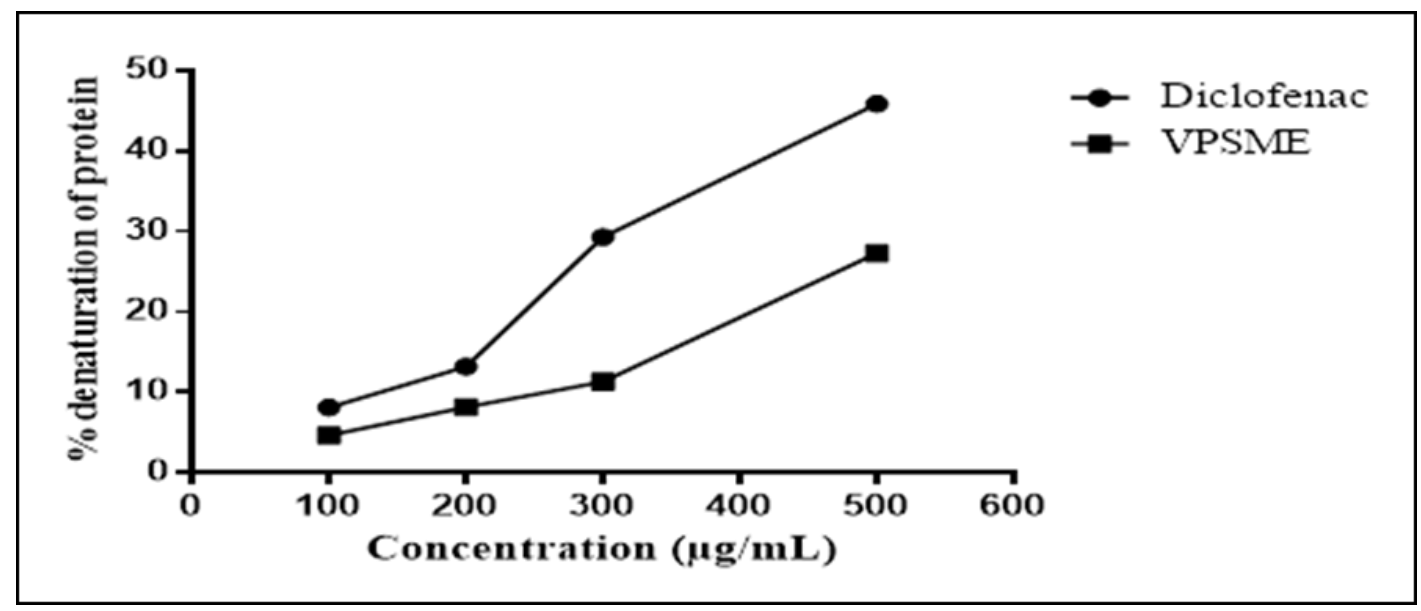

Figure 1 Percentage inhibition of thermal-induced protein denaturation by Diclofenac sodium and methanol extract of V. paradoxa seed

Data from Figure 2 exhibited that diclofenac sodium (2-[(2,6-dichlorophenyl) amino] benzene acetic acid sodium salt) and the methanol extract stabilized HRBC membrane against hypotonicity-induced hemolysis in a concentrationdependent manner. The data in figure 2 shows that the methanol extract stabilized HRBC membrane against hypotonic induced haemolysis in a blood sample than Diclofenac sodium. In addition, methanol extract of $V$. paradoxa seed (IC ${ }_{50}=$ $31.47 \mu \mathrm{g} / \mathrm{mL}, \mathrm{P}<0.05$ ) had higher membrane stabilization capacity than Diclofenac sodium $(\mathrm{IC} 50=33.89 \mu \mathrm{g} / \mathrm{mL})$.

Data from figure 3 showed that the methanol extract (Mean \pm SEM) had a significantly $(\mathrm{P}<0.05)$ high radical scavenging activity. The methanol extract exhibited a significant concentration dependent inhibition of DPPH activity. The maximum percentage inhibition of methanol extract and ascorbic acid were found to be at $97 \%$ and $98 \%$ respectively at $100 \mu \mathrm{g} / \mathrm{mL}$. Furthermore, ascorbic acid ( $\mathrm{IC}_{50}=6.72 \mu \mathrm{g} / \mathrm{mL}$ ) exhibited higher inhibition of DPPH than methanol extract of $V$. paradoxa seed ( $\mathrm{IC}_{50}=8.95 \mu \mathrm{g} / \mathrm{mL}$ ). 


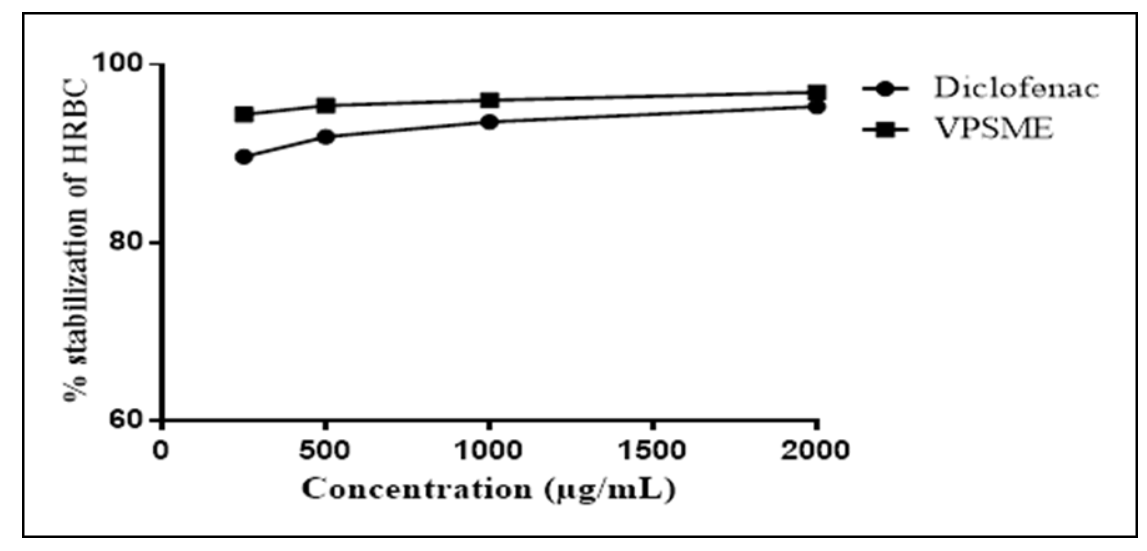

Figure 2 Percentage stabilization of hypotonicity-induced hemolysis of human red blood cell membrane by Diclofenac sodium and methanol extract of $\mathrm{V}$. paradoxa seed

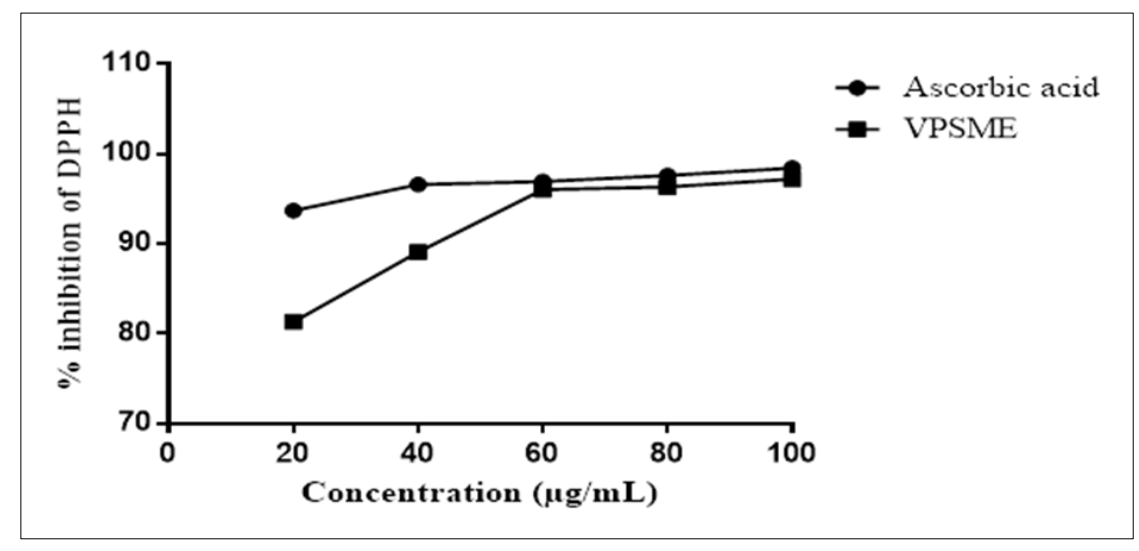

Figure 3 Percentage inhibition of 1'1'-diphenyl-2-picrylhydrazyl radical by methanol extract of V. paradoxa seed and Ascorbic acid

Data from figure 4 showed the ferric reducing capacities of $20-100 \mu \mathrm{g} / \mathrm{mL}$ ascorbic acid and methanol extract of V. paradoxa seed. The absorbances (Mean \pm SEM) exhibited by the methanol extract and ascorbic acid range between $(0.134 \pm 0.006-0.837 \pm 0.032)$ and $(0.174 \pm 0.043-0.761 \pm 0.016)$ respectively at $552 \mathrm{~nm}$

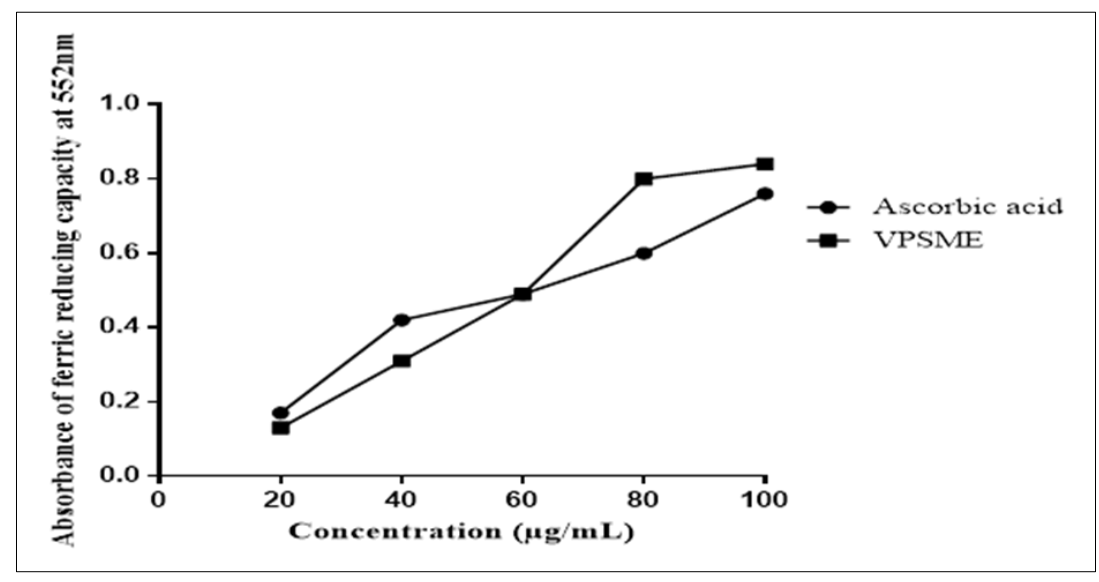

Figure 4 Ferric reducing antioxidant potentials of methanol extract of $V$. paradoxa seed and Ascorbic acid

Data from figure 5 showed that the methanol extract of $V$. paradoxa seed (Mean \pm SEM) had a significantly $(\mathrm{P}<0.05$ ) high inhibition of lipid peroxidation. The maximum percentage inhibition of methanol extract and ascorbic acid were 
$97.5 \%$ and $99 \%$ respectively at concentration of $20 \mu \mathrm{g} / \mathrm{ml}$. Also, methanol extract of $V$. paradoxa seed $\left(\mathrm{IC}_{50}=51.79\right.$ $\mu \mathrm{g} / \mathrm{mL}$ ) exhibited higher antioxidant potential than ascorbic acid $\left(\mathrm{IC}_{50}=52.30 \mu \mathrm{g} / \mathrm{mL}\right)$. Low $\mathrm{IC}_{50}$ value indicate a high level of antioxidant activity.

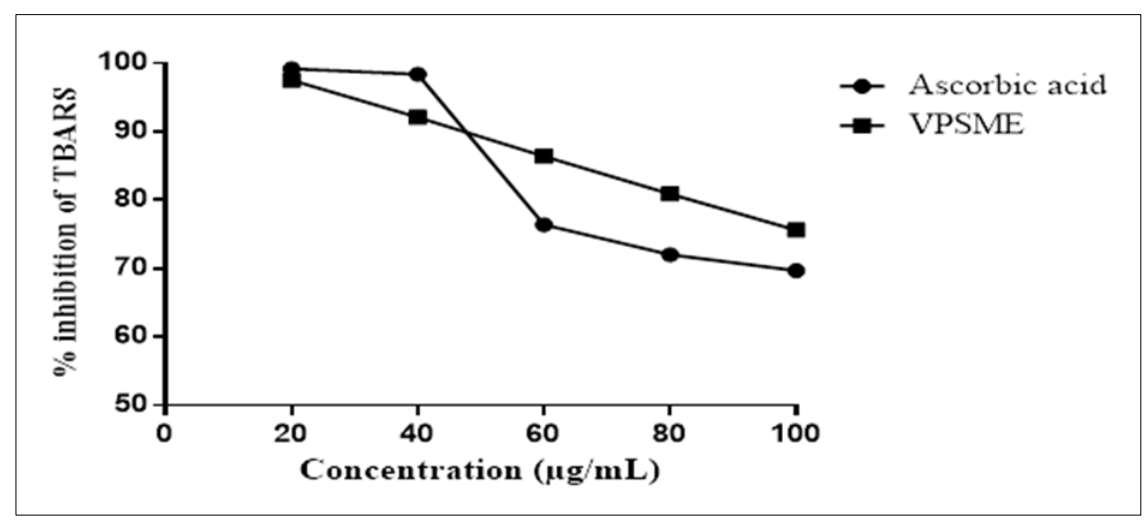

Figure 5 Percentage inhibition of Thiobarbituric acid by Ascorbic acid and methanol extract of V. paradoxa seed

Data from figure 6 showed that the methanol extract of $V$. paradoxa seed had a significantly low $(0.249 \pm 0.04 \mathrm{mg}$ ascorbic acid equivalent $[\mathrm{AAE}] / \mathrm{g}, \mathrm{P}<0.05)$ total antioxidant capacity than the standard $(0.838 \pm 0.03 \mathrm{mgAAE} / \mathrm{g})$ at the highest concentration of $100 \mu \mathrm{g} / \mathrm{mL}$. Although the TAC of both ascorbic acid and VPSME was exhibited in a concentration dependent manner, $20 \mu \mathrm{g} / \mathrm{mL}-100 \mu \mathrm{g} / \mathrm{mL}$.

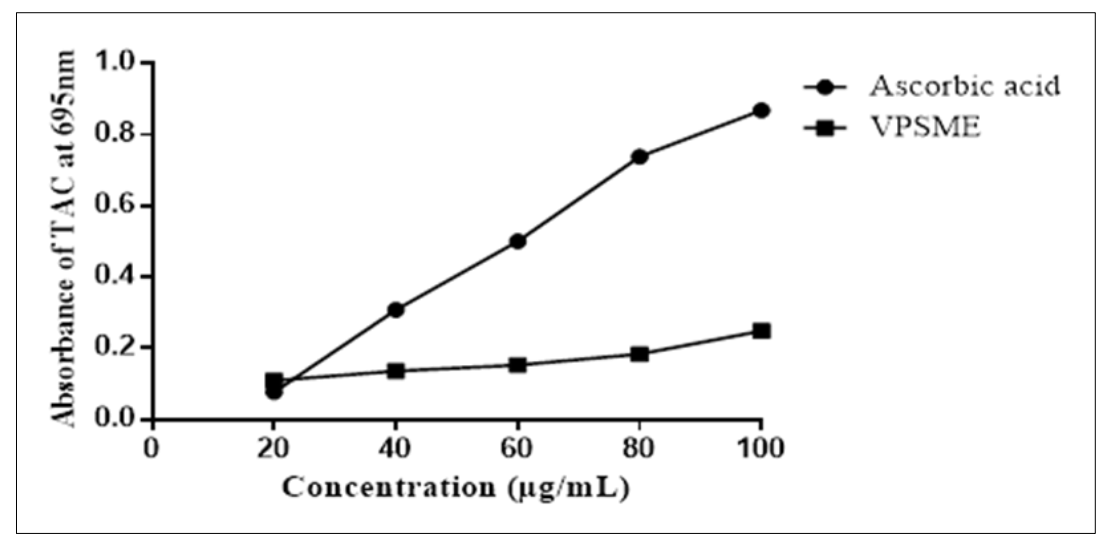

Figure 6 Total antioxidant capacities of methanol extract of Vitellaria paradoxa seed and ascorbic acid

Data from Table 1 showed the IC 50 values of methanol extract of Vitellaria paradoxa seed and ascorbic acid on inhibition of TBARS, DPPH, anti-denaturation of BSA and HRBC stabilization at $\mathrm{P}<0.05$.

Table 1 IC $_{50}$ of methanol extract of Vitellaria paradoxa seed and ascorbic acid on inhibition of TBARS, DPPH, anti-denaturation of BSA and HRBC stabilization

\begin{tabular}{|l|l|l|l|l|}
\hline Test samples & \multicolumn{2}{|c|}{ IC 50} \\
\cline { 2 - 5 } & $\begin{array}{c}\text { DPPH assay } \\
\mathbf{( 2 0 - 1 0 0} \\
\boldsymbol{\mu g} / \mathbf{m L})\end{array}$ & $\begin{array}{c}\text { TBARS assay } \\
\mathbf{( 2 0 - 1 0 0} \boldsymbol{\mu g} / \mathbf{m L})\end{array}$ & $\begin{array}{c}\text { Anti-denaturation of } \\
\text { BSA assay (100-500 } \\
\mathbf{\mu g} / \mathbf{m L})\end{array}$ & $\begin{array}{c}\text { Stabilization of } \\
\text { HRBC assay } \\
(\mathbf{5 0 0 - 2 0 0 0} \boldsymbol{\mu g} / \mathbf{m L})\end{array}$ \\
\hline Ascorbic acid & 6.723 & 52.30 & & 31.47 \\
\hline VPSME & 8.95 & 51.79 & 303.0 & 33.89 \\
\hline Diclofenac sodium & & 261.4 & \\
\hline
\end{tabular}




\section{Discussion}

The antioxidant and anti-inflammatory activities are very important for humans because the oxidative stress and the inflammatory process were generated during different infectious diseases [16]. The release and proliferation of oxidants as free radicals has in part revealed the mechanism of tissue inflammation injury. These chemical radicals are key mediators in provoking or sustaining inflammatory processes, and consequently, their neutralization by phytoantioxidants may attenuate inflammatory response [17]. The result of this study revealed the methanol extract of Vitellaria paradoxa seed may possess profound anti-inflammatory and antioxidant activities [18]. As part of the investigation on the anti-inflammatory activity of methanol extract of $V$. paradoxa seed, the inhibition of protein denaturation and stabilization of human erythrocyte were studied. Most biological proteins lose their biological function when denatured. Denaturation of proteins is a well-documented cause of inflammation. High temperature causes denaturation of BSA (bovine serum albumin) and this denatured protein exhibits the antigens similar to the type III hyper-sensitive reactions [19]. Heat denatured proteins causes delayed hypersensitivity which is associated to diseases like glomerulonephritis, serum disease and rheumatoid arthritis [20]. This study have revealed that the methanol extract of $V$. paradoxa had significant protein denaturation activity compared to the standard Diclofenac sodium. The human red blood cell membrane stabilization assay is studied because the erythrocyte membrane is analogous to the lysosomal membrane and its stabilization implies that the methanol extract may as well stabilize the lysosomal membrane. Stabilization of lysosomal membrane is important in limiting the inflammatory response by preventing the release of lysosomal constituents of activated neutrophil, which causes further tissue inflammation and damage upon cellular release [18]. The methanol extract had significant membrane stabilizing activity which was compared to the standard, Diclofenac sodium. The result showed that the methanol extract had higher stabilization activity than the standard drug which prove that the $V$. paradoxa seed may possess high anti-inflammatory activities.

Generation of free radicals or reactive oxygen species (ROS) during metabolism beyond the antioxidant capacity of a biological system results in oxidative stress [16]. Antioxidants either scavenge the reactive oxygen species or reduce the free radicals. Low levels of antioxidant in the living system assists the development of ageing related diseases such as atherosclerosis, cancers, heart diseases, diabetic neuropathy, aging and Alzheimer's disease. An anticipated solution to such problem is the enhancement of antioxidant that is present in plants [20]. There is a complex mechanism of scavenging free radicals in the human body and consists of a group of enzymes. Consequently, four different assays have been used in this study to reveal the in vitro antioxidant scavenging activities of methanol seed extract of $V$. paradoxa. Bleaching of DPPH solution is extensively used to estimate the electron donating ability of natural plants [21]. The electron donating capacity and concentration of the active constituent in the natural plants contributes towards the free radical scavenging activity. In this study, methanol seed extract of $V$. paradoxa showed significant scavenging ability and was compared with Ascorbic acid which suggested the presence of hydrogen donating constituents. Other plant extracts have been shown to reduce ferric ion and donate $\mathrm{H}^{+}$to DPPH as a mechanism of scavenging these unstable chemicals [22].

FRAP assay measures the reducing capacity by increased sample absorbance based on the formed ferrous ions. The change in absorbance at $593 \mathrm{~nm}$ is attributed to the formation of blue coloured Fe ${ }^{2+}$-TPTZ complex from the colourless oxidized $\mathrm{Fe}^{3+}$ form by the action of electron donating antioxidants [23]. Higher degree of colour formation indicates the more reducing power of that antioxidant. The result of this study showed that methanol extract of $V$. paradoxa seed had a significantly high ferric-reducing antioxidant power compared to the Ascorbic acid standard. Since FRAP assay is easily reproducible and linearly related to molar concentration of the antioxidant present, thus it can be reported that methanol extract of $V$. paradoxa seed may act as free radical scavenger, capable of transforming reactive free radicals into stable non radical products [24].

Phosphomolybdenum assay is an additionally important in vitro antioxidant assay to evaluate the total antioxidant capacity of the methanol seed extract. The assay is based on the reduction of molybdenum (VI) phosphate to molybdenum (V) phosphate by the methanol extract and subsequent formation of a bluish green coloured molybdenum (V) phosphate complex at acid pH [15]. It involves in thermally generating auto-oxidation during prolonged incubation period are higher temperature [25]. It gives direct estimation of the reducing capacity of antioxidant. According to this study, methanol extract of $V$. paradoxa seed exhibit significant total antioxidant capacity compared to Ascorbic acid standard. This event could be attributed to the readiness of antioxidant phytochemicals present in the test extract to donate a hydrogen ion to the reactive molybdenum (VI) [15].

The TBARS assay has been used to measure the degree of lipid peroxidation. Polyunsaturated lipid contents of the biological membrane are susceptible to oxidative reaction of free radicals, which leads to lipid peroxidation [26]. Products of lipid peroxidation such as malondialdeyde (MDA), 4-hydroxyl 2-ninenal, and some other alkanes react with cell macromolecules to form adducts with significant irreversible effects on cellular functions [27, 28]. Consequently, 
the formation of adduct leads to membrane permeability, oxidative nucleic acid damage and eventually to mutation and cancer [29]. Inhibition of lipid peroxidation by methanol extract of $V$. paradoxa seed was very significant compared to Ascorbic acid standard. For TBARS assay, low or reducing absorbance value indicate a high level of antioxidant activity [30]. It will however be necessary to study the structural properties of the active compounds responsible for these activities and investigate their mechanism of actions.

\section{Conclusion}

The results of our investigations reveal that the methanol extract of $V$. paradoxa may contain vital bioactive metabolites including phenolic compounds with significant antioxidant and anti-inflammatory activities which could be helpful in the management of oxidative and inflammatory disorders and constitutes a potential source for development of new treatment agents.

\section{Compliance with ethical standards}

\section{Acknowledgments}

We hereby acknowledge the Department of Biochemistry, Babcock University, which provided the laboratory space that enabled this research to be successfully conducted.

\section{Disclosure of conflict of interest}

There is no conflict of interest amongst the authors as all the authors contributed in one way or the other in conducting the research and in writing the manuscript which was eventually articulated and submitted for publication by the corresponding author.

\section{Statement of ethical approval}

This research is in full compliance with ethical standards and was approved by Babcock University Health Research Ethics Committee.

\section{References}

[1] Ahn K. The worldwide trend of using botanical drugs and strategies for developing global drugs. BMB Reports. 2017; 50(3): 111-116.

[2] Hill AF. Economic Botany: A textbook of useful plants and plant products. New york: McGraw-Hill Book Company. 1952.

[3] Edeoga HO, Okwu DE, Mbaebie BO. Phytochemical constituents of some Nigerian medicinal plants. African Journal of Biotechnology. 2005; 4(7): 685-688.

[4] Smith-Hall C, Larsen H, Pouliot M. People, plants and health: a conceptual framework for assessing changes in medicinal plant consumption. Journal of Ethnobiology and Ethanomedicine. 2012; 8(1): 43.

[5] Nahm HS, Hector RJ, James ES. Effect of selected synthetic and natural antioxidants on the oxidative stability of shea butter (Vitellaria paradoxa subsp. paradoxa). Journal of Medically Active Plants. 2012; 1(2): 69-75.

[6] Adainoo B. Shea Fruit and Shea Butter: Nutritional and Health Benefits you Didn't Know [Internet]. [cited 2021 March 09].

[7] Esuoso KO, Lutz H, Bayer E, Kutubuddin M. Unsaponifiale lipid constitients of some underutilized tropical seed oils. Journal of Agricultural and Food Chemistry. 2000; 48(2): 232-234.

[8] Sabry ME. Biochemistry of free radicals and oxidative stress. Science International. 2013; 1(5): 111-117.

[9] Batlouni M. Nonsteroidal anti-inflammatory drugs: cardiovascular, cerebrovascular and renal effects. Arquivos Brasileiros de Cardiologia. 2010; 94(4): 522-563.

[10] Ramalingam R, Madhavi BB, Nath AR, Duganath N, Sri EU, Banji D. In-vitro anti-denaturation and antibacterial activities of Zizyphus oenoplia. Pharmaceutical Letters. 2010; 2: 87-93.

[11] Oyedapo 0. Red blood cell membrane stabilizing potentials of extracts of Lantana camara and its fractions. International Journal of Plant Physiology and Biochemistry. 2010; 2: 46-51. 
[12] Molyneux P. The use of the stable free radical diphenylpicryl-hydrazyl (DPPH) for estimating antioxidant activity. Songklanakarin Journal of Science and Technology. 2004; 26: 211-219.

[13] Benzie IF, Strain JJ. Ferric reducing antioxidant power assay: direct measure of total antioxidant activity of biological fluids and modified version for simultaneous measurement of total antioxidant power and ascorbic acid concentration. Methods in Enzymology. 1999; 299: 15-27.

[14] Hodges DM, DeLong JM, Forney CF, Prange RK. Improving the thiobarbituric acid-reactive-substances assay for estimating lipid peroxidation in plant tissues containing anthocyanin and other interfering compounds. Planta. 1999; 207: 604-611.

[15] Prieto P, Pineda M, Aguilar M. Spectrophotometric quantitation of antioxidant capacity through the formation of Phosphomolybdenum complex: Specific application to the determination of Vitamin E. Journal of Analytical Biochemistry. 1999; 269(2): 337-341.

[16] Mashhadi NS, Ghiasvand R, Askari G, Hariri M, Darvishi L, Mofid MR. Anti-Oxidative and Anti-Inflammatory Effects of Ginger in Health and Physical Activity: Review of Current Evidence. International Journal of Preventive Medicine. 2013; 4: S36-S42.

[17] Kehrer JP, Klotz LO. Free radicals and related reactive species as mediators of tissue injury and disease: Implications for Health. Critical Review of Toxicology. 2015; 45: 765-798.

[18] Leelaprakash G, Dass SM. In vitro antiinflammatory activity of methanol extract of Enicostemma axillare. International Journal of Drug Development and Resources. 2011; 3(3): 189-196.

[19] Tahir I, Khan MR, Shah NA, Aftab M. Evaluation of phytochemicals, antioxidants activity and amelioration of pulmonary fibrosis with Phyllanthus emblica leaves. BMC Complement and Alternative Medicine. 2016; 16(1): 406.

[20] Shah M, Parveen Z, Khan MR. Evaluation of antioxidant, anti-inflammatory, analgesic and antipyretic activities of stem bark of Sapindus mukorossi. BMC Complement and Alternate Medicine. 2017; 17(1): 526.

[21] Amir 0, Zekhnini A, Bouhaimi A, Tahrouch S, Hatimi A. Anti-inflammatory activity of methanolic extract from Pistacia atlantica Desf. Leaves. Journal of Pharmacology and Phamacognosy. 2018; 10(1): 71-76.

[22] Fadda A, Serra M, Molinu MG, Azara E, Barberis A, Sanna D. Reaction time and DPPH concentration influence antioxidant activity and kinetic parameters of bioactive molecules and plant extracts in the reaction with the DPPH radical. Journal of Food Composition \& Analysis. 2014; 35: 112-119.

[23] Gupta AD, Pundeer V, Bander G, Dhar S, Ranganath IR, Kumari GS. Development ot new drug: Assessment of antioxidant capacity using FRAP assay. Journal of Pharmacology. 2009; 1: 200-208.

[24] Engoor SA, Mangalanandan SL, Paul HC, Jagathala MS. In vitro antioxidant, anti-lipid peroxidation activities and HPLC analysis of methanol extracts from bark and stem of Mahonia leschenaltia tekeda. Asian Journal of Plant Science and Research. 2013; 3(2): 116-126.

[25] Phatak RS, Hendre AS. Total antioxidant capacity (TAC) of fresh leaves of Kalanchoe pinnata. Journal of Pharmacognosy and Phytochemistry. 2013; 2(5): 32-35.

[26] Gangwar M, Gautam MK, Sharma AK, Tripathi YB, Goel RK, Nath G. Antioxidant capacity and radical scavenging effect of polyphenol rich Mallotus philipenensis fruit extract on human erythrocytes: An in vitro study. The Scientific World Journal. 2014; 14(1): 253-265.

[27] Onyema OO, Farombi EO, Emerole GO, Ukoha AI, Onyeze GO. Effect of vitamin E on monosodium glutamate induced hepatotoxicity and oxidative stress in rats. Indian Journal of Biochemistry and Biophysics. 2006; 43: 2024.

[28] Tuma DJ, Casey CA. Dangerous by products of alcohol breakdown - focus on adducts. Alcohol Research and Health. 2003; 27(4): 285-290.

[29] Halliwell B, Gutteridge JM. Lipid peroxidation, oxygen radicals, cell damage and antioxidant therapy. Journal of Analytical Biochemistry. 1984; 1: 1396-1397.

[30] Badmus JA, Odunola OA, Yekeen TA, Gbadegesin AM, Fatoki JO, Godo MO, Hiss DC. Evaluation of antioxidant, antimutagenic and lipid peroxidation inhibitory activities of selected fractions of Holarrhena floribunda (G. Don) leaves. ACTA Biochimica Polonica. 2013; 60(3): 435-442. 